\title{
Burnout is Associated with Amount of Work and Sleep Quality of Public-school Dentists in the Caraga Region
}

\author{
Junhel Dalanon, DMD, MAT, EdD, PhD (cand. $)^{1,2}$ and Yoshizo Matsuka, DDS, PhD² \\ ${ }^{1}$ School of Dentistry, Southwestern University PHINMA \\ ${ }^{2}$ Department of Stomatognathic Function and Occlusal Reconstruction, Tokushima University Graduate School, Japan
}

\begin{abstract}
Objectives. Public health dentists in the Philippines are being made to treat more patients and do other tasks despite being underpaid. Despite this, there is a dearth of information on burnout and its association with Filipino public-school dentists. Thus, this study aimed to assess the burnout levels and their association with the amount of work and sleep quality.
\end{abstract}

Methods. There were 10 out of 14 dentists from the Caraga Region who responded and answered a self-directed and self-reported online questionnaire composed of 52 questions that gauged sociodemographic data, sources of burnout, level of burnout, lower back pain, and sleep quality.

Results. Based on the results of the study, dentists with more than 40,000 patients ( $r s=0.81, p=0.005$ ), in charge of more than one municipality ( $r s=0.67, p=0.035)$ and more than one school $(r s=0.67, p=0.035)$, and with poor sleep ( $r s=1, p=0.005)$ experience more burnout.

Conclusion. The level of burnout is high in Filipino public-school dentists. In this study, burnout was associated with dentists who have poor sleep, having to serve more than 40,000 patients, more than one municipality, and more than one school. The legal bases for oral health and other pertinent memorandum orders from concerned government organizations should be revisited.

Key Words:

\section{INTRODUCTION}

The Universal Health Care (UHC) Act (Republic Act No. 11223) has been passed into law recently and affords for much-needed reforms in the health system of the country. ${ }^{1}$ Despite the perceived improvement to health access and enhancement in health policy, the oral health component has not been prioritized. Apart from having the word "dentist" appearing only once in the law, a great part of the population still relies on out-of-pocket

Paper presented at the $40^{\text {th }}$ International Association for Human Caring (IAHC) Conference on May 31, 2019, Greenville, South Carolina, USA.

Recipient of the IAHC Shirley Gordon Award.

Corresponding author:

Junhel Dalanon, DMD, MAT, EdD, PhD (cand.)

School of Dentistry

Southwestern University PHINMA

Urgello St., Cebu City, Philippines 6000

Email: jcdalanon@swu.edu.ph payments for dental services. Notwithstanding the mandate of Republic Act (RA) 3814, RA 5211, and RA 9484 (Philippine Dental Act of 2007), the now-defunct Bureau of Dental Health Services has been replaced by the Dentist Deployment Program (DDP). The DDP is part of the Human Resources for Health (HRH) Deployment Program which sends contractual dentists, physicians, nurses, and other health-allied professionals to both urban and remote places. Underappreciated and under-funded, this becomes a problem for the healthcare managers and the employees. 
The Philippines remains a developing country and healthcare affordability still unreachable. Migration and brain drain problems remain a predicament for the government, while healthcare professionals suffer from chronicity of stress that leads to burnout as a result of workforce depletion brought about by this phenomenon. ${ }^{2}$

Burnout is a complex condition typified by emotional exhaustion and pessimism. It is common in people doing humanitarian work. Emotional exhaustion, depersonalization or caregiver stress, and personal accomplishment are the aspects of burnout. ${ }^{3}$ More severe occupational burnout was seen in primary dentists who are female, younger, single and working as a resident doctor according to a study. ${ }^{4}$ Another study found a link between work stress, marital status, monthly pay, and salary satisfaction with emotional exhaustion. ${ }^{5}$

Most of the work parameters have been focused on the amount of work per number of hours rendered a day. The number of municipalities, the number of patients treated per year, and the number of schools have not been used as parameters for workload. Moreover, the publicschool dentists have not been used as cohorts in the study of burnout. This study aimed to measure the burnout of public-school dentists and their association with sleep quality and the amount of work.

\section{MATERIALS AND METHODS}

\section{Study design and participants}

This study was approved by the institutional review board of Southwestern University PHINMA. All 14 public-school dentists in the Caraga Region were invited in September 2019. The researchers received an overwhelming response from 10 ( $71.4 \%$ response rate) of the dentists. These dentists were requested to partake in a closed online survey composed of 52 questions divided into sociodemographic components (8 questions), sources of burnout (1 question), Copenhagen Burnout Inventory (CBI) (9 question), Oswestry Disability Index (ODI) (10 questions), and Pittsburgh Sleep Quality Index (PSQI) (24 questions). The participants' identities were anonymized using a secure sockets layer encryption and the number of entries restricted to a single instance. An explanatory note was provided, informing the dentists that participation is compulsory and no portion of the research will affect their current employment status. Consent was sought and given willingly through electronic signature embedded in the survey form.

\section{Copenhagen Burnout Inventory}

The CBI assesses the gradation of burnout in the constructs of personal, work, and client domains. ${ }^{6-8}$ In the past, it has demonstrated enough internal consistency, reliability, and concomitant validity. It has been widely used, culturally adapted, and translated to many different languages.

\section{Oswestry Disability Index}

The ODI or Oswestry Low Back Pain Disability Questionnaire is a vital instrument in the measurement of a person's functional disability and has been considered the yardstick for self-reported outcome assessment for low back pain. ${ }^{9-11}$ It is composed of 10 sections that encompass pain intensity, personal care, lifting, walking, sitting, standing, sleeping, sex life, social life, and traveling. Each section can have a high score of five for a grand total of 50 . The total score is summed, divided by 50 , and multiplied by 100 to get the percentage. The score is interpreted as minimal disability (0-20\%), moderate disability (21-40\%), severe disability (41-60\%), crippled (61-80\%), and bed-bound or exaggerating (81-100\%).

\section{Pittsburgh Sleep Quality Index}

The PSQI is a widely used, psychometric-tested, valid, and reliable measure of sleep quality. ${ }^{12}$ It has been used in various cultures, languages, and cohorts. ${ }^{13-16}$ The questionnaire is divided into two sections. The first set of questions consists of 19 items to be answered by the participant and five queries to be answered by a bed-mate. The first part includes the seven components of sleep: subjective sleep quality, sleep latency, sleep duration, habitual sleep efficiency, sleep disturbances, use of sleeping medication, and daytime dysfunction. A high number of three and a low of zero determines the quality of sleep. The possible score or global sleep quality index (GSQI) ranges from zero to 21 in which a score greater than five means poor sleep.

\section{Data analyses}

Sociodemographic and work-related variables were tabulated and subjected to either one-sample binomial test, one-sample $\mathrm{X}^{2}$ test, and one-sample Kolmogorov-Smirnov test. A one-sample t-test was used to compare samples within each component of burnout, low back pain, and sleep quality. Kruskal-Wallis $\mathrm{H}$ test was used to check for significant differences among dentists' burnout based on the number of patients treated in a year, number of municipalities, number of schools, and GSQI. Spearman's correlation was used to check for the association between burnout and the chosen variables (number of patients treated in a year, number of municipalities, number of schools, ODI, and GSQI). The sources of burnout were graphed in a histogram for analysis. All tests were done using SPSS 21.

\section{RESULTS}

\section{Sociodemographic and work-related profile}

Majority of the Caraga Region public-school dentists were females, married than single, 41-50 years old, bachelor's degree holder, earning Php30,000-39,999 salary per month, and with 40,000-49,999 patients, more than one municipality, and more than one school (Table 1). 
Table 1. Sociodemographic and work-related profile of the participants, $n=10$

\begin{tabular}{|c|c|c|c|}
\hline Variables & $f(\%)$ & $\begin{array}{l}\text { Mean } \pm \text { SD } \\
\text { (Range) }\end{array}$ & p-value \\
\hline $\begin{array}{l}\text { Sex } \\
\text { Female } \\
\text { Male }\end{array}$ & $\begin{array}{l}9(90) \\
1(10)\end{array}$ & $0.1 \pm 0.32(0-1)$ & $0.021^{* a}$ \\
\hline $\begin{array}{l}\text { Civil status } \\
\text { Single } \\
\text { Married } \\
\end{array}$ & $\begin{array}{l}3(30) \\
7(70) \\
\end{array}$ & $0.7 \pm 0.48(0-1)$ & $0.344^{* a}$ \\
\hline $\begin{array}{l}\text { Age } \\
\qquad 30 \text { years old } \\
31-40 \text { years old } \\
41-50 \text { years old } \\
51-60 \text { years old }\end{array}$ & $\begin{array}{l}2(20) \\
2(20) \\
5(50) \\
1(10)\end{array}$ & $1.5 \pm 0.97(0-3)$ & $0.308^{b}$ \\
\hline $\begin{array}{l}\text { Highest education } \\
\text { Doctor of Dental Medicine }\end{array}$ & $10(100)$ & & \\
\hline $\begin{array}{l}\text { Salary (Php) } \\
30,000-39,999 \\
40,000-49,999\end{array}$ & $\begin{array}{l}8(80) \\
2(20)\end{array}$ & $0.2 \pm 0.42(0-1)$ & $0.344^{a}$ \\
\hline $\begin{array}{l}\text { Patients treated per year } \\
\quad<10,000 \\
10,000-39,999 \\
40,000-49,999 \\
\end{array}$ & $\begin{array}{l}2(20) \\
1(10) \\
7(70)\end{array}$ & $3.1 \pm 1.66(0-4)$ & $0.074^{c}$ \\
\hline $\begin{array}{l}\text { Municipalities } \\
\quad 1 \\
>1\end{array}$ & $\begin{array}{l}3(30) \\
7(70)\end{array}$ & $0.7 \pm 0.48(0-1)$ & $0.047^{*}$ \\
\hline $\begin{array}{l}\text { Schools } \\
1 \\
>1 \\
\end{array}$ & $\begin{array}{l}3(30) \\
7(70)\end{array}$ & $0.8 \pm 0.42(0-1)$ & $0.019^{* c}$ \\
\hline
\end{tabular}

Statistical difference within groups was tested using aone-sample binomial test, bone-sample chi-square test, cone-sample KolmogorovSmirnov test at $p<0.05$ significance

\section{Summary of burnout levels, low back pain, sleep- related factors}

The results reported that majority of these public-school dentists are experiencing personal burnout $(63.9 \pm 17.93$, $\mathrm{p}=0.019)$. But experiences of work burnout $(52.1 \pm 14.19$, $\mathrm{p}=0.941)$, client burnout $(48.4 \pm 22.82, \mathrm{p}=0.514)$, and the presence of lower back pain $(\mathrm{p}=0.628)$ were not significant. The components of sleep quality including subjective sleep quality $(0.9 \pm 0.57, \mathrm{p}=0.001)$, sleep latency $(1.5 \pm 0.71$, $\mathrm{p}=0.000)$, sleep duration $(1.2 \pm 1.14, \mathrm{p}=0.009)$, sleep efficiency $(1.2 \pm 1.23, \mathrm{p}=0.013)$, sleep disturbance $(2.0 \pm 0.94, \mathrm{p}=0.000)$, and daytime dysfunction $(0.9 \pm 0.32, \mathrm{p}=0.000)$ yielded significance except for sleep medication $(0.5 \pm 0.71, \mathrm{p}=0.052)$. Data from the ODI yielded no difference in the low back pain levels of the participants (Table 2).

\section{Differences in the degree of burnout according to work-related variables and sleep quality}

Comparing burnout data with sleep quality and workrelated variables, the results found statistical differences between the number of patients treated per year $(\mathrm{H}(1)=5.86$, $\mathrm{p}=0.015)$, number of municipalities $(\mathrm{H}(1)=4, \mathrm{p}=0.046)$, number of schools $(\mathrm{H}(1)=4, \mathrm{p}=0.046)$, and global sleep quality index scores $(\mathrm{H}(1)=9, \mathrm{p}=0.003)$ (Figure 1$)$.

\section{Associations of burnout}

Based on the results of the study, dentists with more than 40,000 patients $\left(r_{s}=0.81, p=0.005\right)$, in charge of more than one municipality $\left(\mathrm{r}_{\mathrm{s}}=0.67, \mathrm{p}=0.035\right)$ and more than
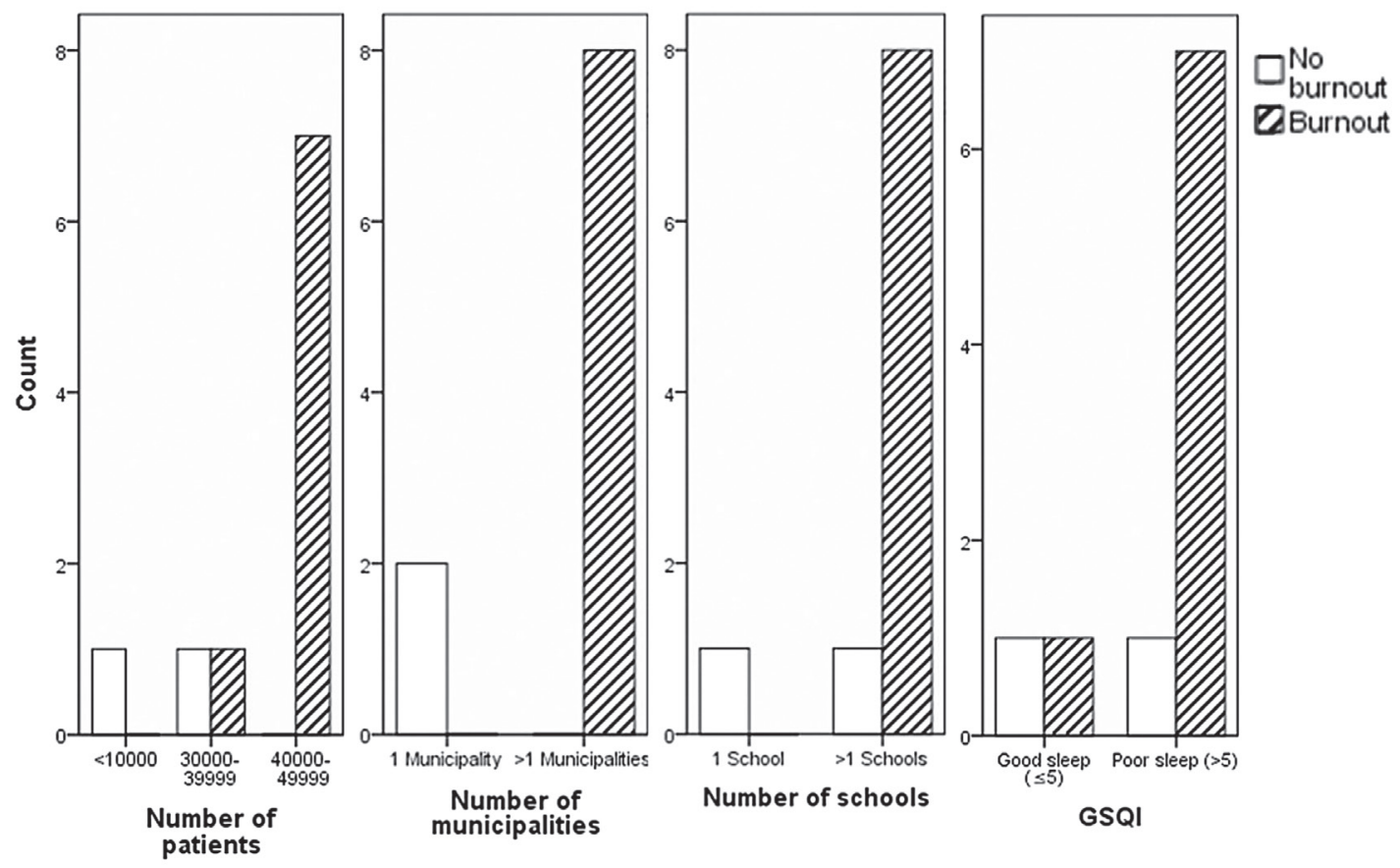

Figure 1. Self-reported burnout of public-school dentists categorized into the number of patients treated per year, number of municipalities, and number of schools. Kruskal-Wallis $\mathrm{H}$ test was used to test for significance within between groups at $p<0.05^{*}$. GSQI=Global Sleep Quality Index 
Table 2. Burnout and sleep quality profile of the respondents,

\begin{tabular}{lcl}
\multicolumn{1}{c}{$\mathrm{n}=10$} & & \\
\hline \multicolumn{1}{c}{ Variables } & Mean \pm SD (Range) & p-value \\
\hline Burnout & & \\
$\quad$ Personal burnout & $63.9 \pm 17.93(38-100)$ & $0.019^{*}$ \\
$\quad$ Work burnout & $52.1 \pm 14.19(36-86)$ & 0.941 \\
$\quad$ Client burnout & $48.4 \pm 22.82(8-100)$ & 0.514 \\
\hline Low back pain & & \\
$\quad$ Oswestry disability index & $0.7 \pm 0.48(0-1)$ & 0.628 \\
\hline Sleep quality & & \\
$\quad$ Subjective sleep quality & $0.9 \pm 0.57(0-2)$ & $0.001^{*}$ \\
Sleep latency & $1.5 \pm 0.71(1-3)$ & $0.000^{*}$ \\
Sleep duration & $1.2 \pm 1.14(0-3)$ & $0.009^{*}$ \\
Sleep efficiency & $1.2 \pm 1.23(0-3)$ & $0.013^{*}$ \\
Sleep disturbance & $2.0 \pm 0.94(1-3)$ & $0.000^{*}$ \\
Sleep medication & $0.5+0.71(0-2)$ & 0.052 \\
Daytime dysfunction & $0.9 \pm 0.32(0-1)$ & $0.000^{*}$ \\
\hline
\end{tabular}

One-sample t-test used to compare samples within each component of burnout, low back pain, and sleep quality at $p<0.05$ one school $\left(r_{s}=0.67, p=0.035\right)$, and with poor sleep $\left(r_{s}=1\right.$, $\mathrm{p}=0.005$ ) experience more burnout (Table 3 ).

\section{Sources of burnout}

Lack of dental materials, lack of staff, being underpaid, too much paperwork, lack of dental chairs, being made to do a job other than being a dentist, and the lack of support from the government were identified as problems in the workplace or sources of burnout (Figure 2). Lack of staff and being underpaid were found to be significant (Figure 3).

\section{DISCUSSION}

As age, gender, and other sociodemographic determinants influence the mental health states, it is important to discuss how these variables affect burnout. For instance, the predominance of females in the dental practice might
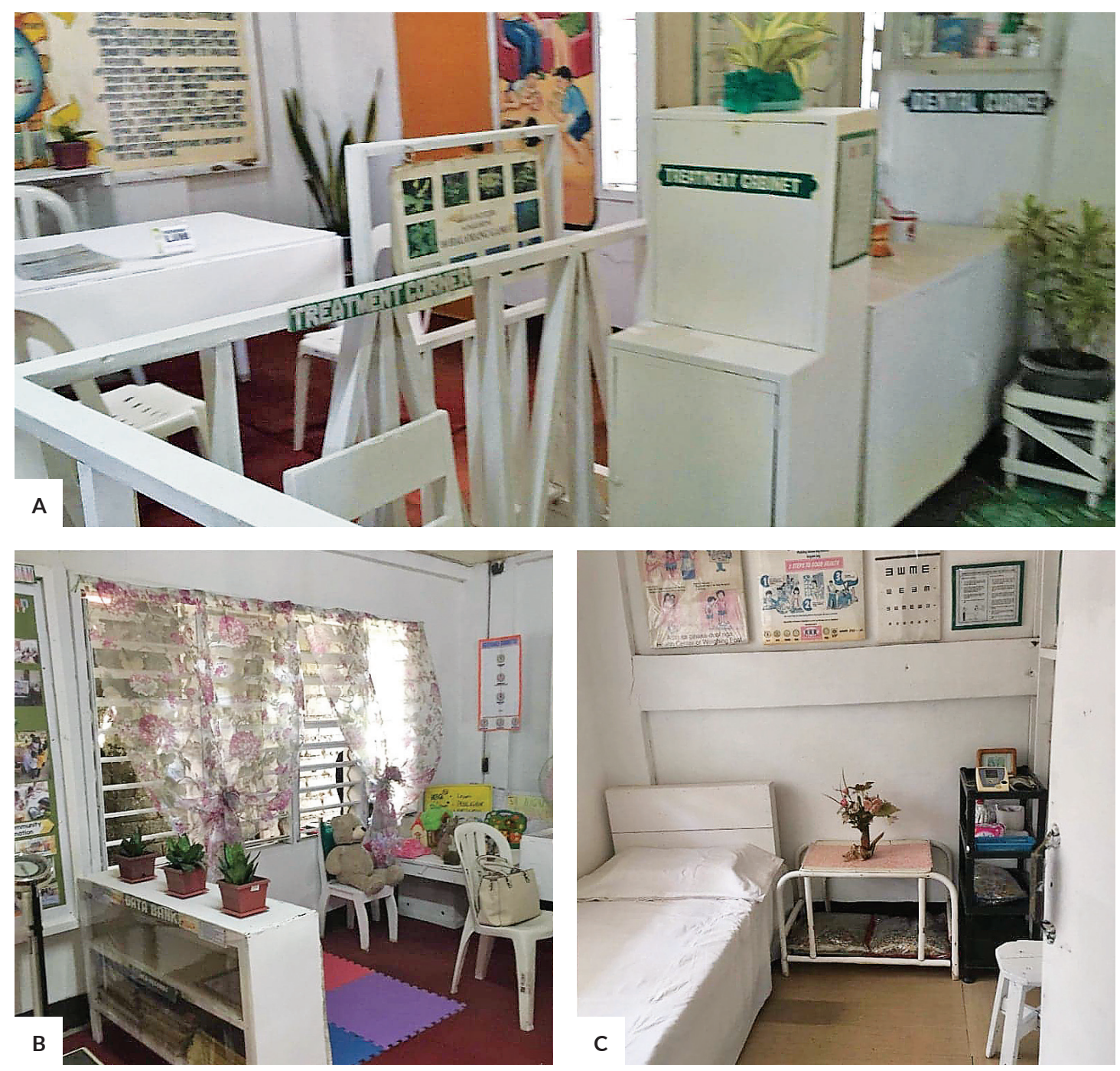

Figure 2. A public school dental clinic in the Caraga region, shown with lack of dental materials and attached to (A) other allied health clinics, (B) lack of equipment, and (C) absence of a dental chair. Note: This set-up and structure may not be representative of all the public school dental clinics in the region. 


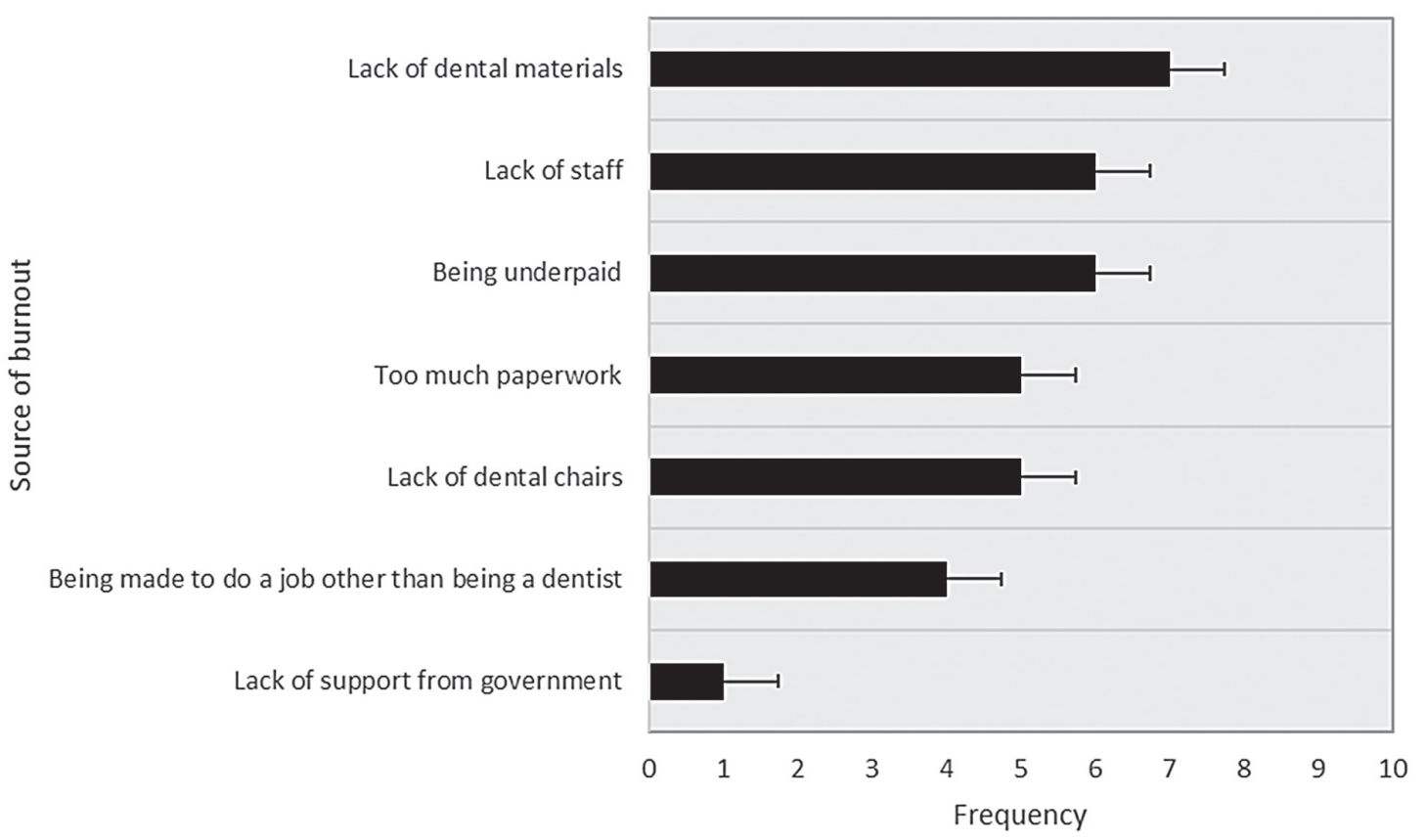

Figure 3. Sources of burnout $(n=10)$ based on multiple-answer questions with dichotomous choices. Nonparametric one-sample binomial test used to test within samples at $p<0.05$.

be brought about by the feminization of dentistry and the prioritization of families in favor of the daughter than the son to pursue a college education. ${ }^{17,18} \mathrm{~A}$ substantial percentage of these dentists are also in their $40 \mathrm{~s}$ and this might contribute to the snowballing effect and chronicity of stress that could lead to burnout.

Burnout is not only common to dentists working in the public schools of the Philippines, but the unrest of publicschool teachers due to work overload has also been well documented. Due to the rigorous nature of the work and being made to work extra other than the job required of a teacher can induce stress. ${ }^{19}$ Stress then is brought at home and promotes the chronicity of physical and psychological exhaustion. The higher levels of burnout in this study can be explained by the predominance of dentists in their 40s. Stress carries through the years and worsens through time thereby producing burnout. While insignificantly small and short-acting stress is a normal part of daily living, the prolonged and severe immersion to stress may be detrimental to one's health. Like the teachers, the dentists in the public- school system also renders services to the number of people beyond the recommended ratio. ${ }^{20}$

The Caraga region is no exemption. There are only 14 dentists across the five administrative districts. Surigao del Norte has the greatest number of dentists with five at a 1:485,088 dentist to patient ratio and 1:45 dentist to school ratio. Next is Agusan del Norte with four dentists at a 1:72,892 dentist to patient ratio and 1:58 dentist to school ratio. The district with the third greatest number of dentists is Surigao del Sur with three dentists at a 1:197,417 dentist to patient ratio and 1:159 dentist to school ratio. Agusan del Sur follows with only two dentists at a 1:350,327 dentist to patient ratio and 1:271 dentist to school ratio. Dinagat islands do not have a dentist. This dentist would have to serve 127,152 patients and 143 schools. ${ }^{21}$ If followed strictly, the dentist to patient ratio of industrialized countries is at 1:200,000 and only Agusan del Norte will pass this provision. Most of these ratios are even absurdly inadequate compared to African countries, where the dentist to population ratio is roughly $1: 150,000$. In most industrialized countries this

Table 3. Correlation of work-related conditions, burnout, low-back pain, and sleep quality, $n=10$

\begin{tabular}{lcccccc}
\hline & Number of patients & Number of municipalities & Number of schools & Burnout & ODI & GSQI \\
Number of patients & 1 & & & & & \\
Number of municipalities & $0.044^{*}$ & 1 & & & & \\
Number of schools & $0.044^{*}$ & $0.005^{*}$ & $0.035^{*}$ & 1 & & \\
Burnout & $0.005^{*}$ & $0.035^{*}$ & 0.545 & 0.545 & 1 \\
ODI & 0.223 & 0.545 & $0.035^{*}$ & $0.005^{*}$ & 0.545 & 1 \\
GSQI & $0.005^{*}$ & $0.035^{*}$ & & & & \\
\hline
\end{tabular}

Spearman's rho at $p<0.05^{*}$ level of significance used to test correlation; ODI=Oswestry disability index, GSQI=Global Sleep Quality Index 
ratio is about 1:2,000. The number of patients assigned to a public school dentist would depend on the number of schools served. The number of schools assigned would depend on the number of municipalities provided. The number of municipalities to be served by a public school dentist will be determined and notified during the job interview by the schools' division superintendent.

This report reveals high levels of stress in public-school dentists, particularly under the personal burnout construct. This is higher than the scores in a study done in Hong Kong dentists but higher in America. ${ }^{22,23}$ This could be due to the type of personality of dentists. Previously, it has been identified that Type $\mathrm{A}$ health professionals or those that exhibit ambition and who are driven to excel in their chosen profession are prone to burnout. ${ }^{24}$ The result of this study is consistent with other studies that yielded a high level of personal burnout and average levels of work burnout and client burnout. ${ }^{24,25} \mathrm{~A}$ study in Australia also stated that personal factors are stronger predictors of burnout. The number of patients treated per year, number of municipalities, and the number of schools were associated with high levels of burnout. These variables were used in the absence of data on the number of hours spent in work in this study. As opposed to private practitioners, these public-school dentists have department heads that impose monthly and yearly objectives to be met. This relates to the burden of practice management in the public health setting. ${ }^{26,27}$

The amount of work can impact the quality of sleep the dentists have. ${ }^{28-31}$ In terms of the components of sleep quality, poor sleep quality is due to subjective sleep quality, sleep latency, sleep efficiency, sleep disturbance, and daytime dysfunction. The GSQI reflects the overall sleep quality of these dentists. If a health worker is unable to have appropriate sleep, it directly affects burnout and indirectly affects the quality of the job done. ${ }^{32}$

Based on probable sources of burnout, the lack of staff and practicing solo can indeed exacerbate the chronicity of burnout (Figure 3). ${ }^{33}$ In addition to the lack of help in the dental infirmary, financial situations can also affect the onset and persistence of psychological exhaustion..$^{27,34,35}$ In the Philippines, a public health dentist receives a salary grade 14 (Dentist I) and can go only as high as salary grade 22 (Dental Program Supervisor) or salary grade 28 (Dentist VII). In reference, an entry-level nurse earns a salary grade 11 but maybe bumped to salary grade 15 starting $2020 .{ }^{36}$ While a physician can enter at salary grade 16 as a Medical Officer 1 and as high as salary grade 30 (Medical Specialist VII). ${ }^{37}$ This will prompt the dentist to migrate and seek viable options for livelihood elsewhere, thereby producing a shortage of manpower that is already depleted. According to the Philippine HRH Master Plan for 2030, there are currently only 1,286 vacant positions for dentists as opposed to 6,901 for the doctors and 12,159 for the nurses in the Department of Health. From 8,629 projected dentists in 2005, the expected 2030 workforce will reach 12,802 only.
This does not fare well if compared to the projections of the physicians and nurses. From 30,525 physicians in 2005 there will be 47,151 in 2030 , while the 170,423 existing nurses in 2005 will be 263,244 in 2030 . The cost of training physicians in 2030 will be 765.61 billion pesos, about 35.02 billion pesos for the nurse, and only 5.65 billion pesos for dentists. The discrepancy in salaries are even greater as the total amount of physicians' salaries will reach 36.07 billion pesos, nurses' salaries at 214.60 billion pesos, and dentists' salaries at 8.85 billion pesos only. ${ }^{38}$

The public-school dentists and the dental profession, in general, are disadvantaged in the Philippines. Regardless of the high caries prevalence and number of Filipinos suffering from edentulism, oral health care as a component of public health is still being deliberately forgotten or underprioritized. If this continues, the oral health status of the Philippines will continue to worsen. Prospective exploratory studies should be directed at unraveling the determinants of burnout in Filipino dentists through regression analysis. Considering gender and age as determinants of burnout, as well as increasing the amount or variance in educational attainment, might be a good direction to understand burnout. As participants were drawn from a single region, inferences on a nationwide scale could not be done. In addition, a nationwide survey with a qualitative component should be done to increase the statistical power.

\section{CONCLUSION}

The level of burnout is high in Filipino public-school dentists in the Caraga region. A significantly higher number of dentists experience personal burnout than work burnout or client burnout. In this study, burnout was associated with dentists who have poor sleep, having to serve more than 40,000 patients, more than one municipality, and more than one school. Lack of staff and being underpaid was found to be a significant source of burnout in this cohort. The legal bases for oral health and other pertinent memorandum orders from concerned government organizations should be revisited.

\section{Statement of Authorship}

The author approved the final version submitted.

\section{Author Disclosure}

The author declared no conflicts of interest.

\section{Funding Source}

This paper was partially funded by the International Association for Human Caring Shirley C. Gordon Award.

\section{REFERENCES}

1. Philippines Cot. An act instituting universal health care for all Filipinos, prescribing reforms in the health care system, and appropriating funds therefor. [Internet] 2018 [cited 2019 June 27] 
Available from: https://www.officialgazette.gov.ph/downloads/2019/ 02feb/20190220-RA-11223-RRD.pdf.

2. Castro-Palaganas E, Spitzer DL, Kabamalan MM, et al. An examination of the causes, consequences, and policy responses to the migration of highly trained health personnel from the Philippines: the high cost of living/leaving-a mixed method study. Hum Resour Health. 2017;15(1):25.

3. Gordon SC. Shared vulnerability: a theory of caring for children with persistent head lice. J Sch Nurs. 2007;23(5):283-92.

4. Lu L, Lee HM, Shieh TY. Occupation stress, health and occupational burnout among dentists: A study of clinical dentists in Kaohsiung. Applied Psychology. 2005;27:59-80.

5. Chen YY, Kawachi I, Subramanian SV, Acevedo-Garcia D, Lee YJ. Can social factors explain sex differences in insomnia? Findings from a national survey in Taiwan. J Epidemiol Community Health. 2005;59(6):488-94.

6. Papaefstathiou E, Tsounis A, Malliarou M, Sarafis P. Translation and validation of the Copenhagen Burnout Inventory amongst Greek doctors. Health Psychol Res. 2019;7(1):7678.

7. Jeon GS, You SJ, Kim MG, Kim YM, Cho SI. Psychometric properties of the Korean version of the Copenhagen Burnout Inventory in Korean homecare workers for older adults. PLoS One. 2019;14(8):e0221323.

8. Javanshir E, Dianat I, Asghari-Jafarabadi M. Psychometric properties of the Iranian version of the Copenhagen Burnout Inventory. Health Promot Perspect. 2019;9(2):137-42.

9. Fairbank JC, Couper J, Davies JB, O'Brien JP. The Oswestry low back pain disability questionnaire. Physiotherapy. 1980;66(8):271-3.

10. Mousavi SJ, Parnianpour M, Mehdian H, Montazeri A, Mobini B. The Oswestry Disability Index, the Roland-Morris Disability Questionnaire, and the Quebec Back Pain Disability Scale: translation and validation studies of the Iranian versions. Spine (Phila Pa 1976). 2006;31(14):E454-9.

11. Vincent JI, Macdermid JC, Grewal R, Sekar VP, Balachandran D. Translation of oswestry disability index into Tamil with cross cultural adaptation and evaluation of reliability and validity (section sign). Open Orthop J. 2014;8:11-9.

12. Buysse DJ, Reynolds CF, 3rd, Monk TH, Berman SR, Kupfer DJ. The Pittsburgh Sleep Quality Index: a new instrument for psychiatric practice and research. Psychiatry Res. 1989;28(2):193-213.

13. Plumb TR, Peachey JT, Zelman DC. Sleep disturbance is common among servicemembers and veterans of Operations Enduring Freedom and Iraqi Freedom. Psychol Serv. 2014;11(2):209-19.

14. Mellor A, Waters F, Olaithe M, McGowan H, Bucks RS. Sleep and aging: examining the effect of psychological symptoms and risk of sleep-disordered breathing. Behav Sleep Med. 2014;12(3):222-34.

15. Kilicaslan EE, Esen AT, Kasal MI, Ozelci E, Boysan M, Gulec M. Childhood trauma, depression, and sleep quality and their association with psychotic symptoms and suicidality in schizophrenia. Psychiatry Res. 2017;258:557-64.

16. Del Rio Joao KA, de Jesus SN, Carmo C, Pinto P. Sleep quality components and mental health: Study with a non-clinical population. Psychiatry Res. 2018;269:244-50.

17. McKay JC, Quinonez CR. The feminization of dentistry: implications for the profession. J Can Dent Assoc. 2012;78:c1.

18. Alampay LP, Garcia AS. Education and Parenting in the Philippines. In: Sorbring E, Lansford JE, eds. School Systems, Parent Behavior, and Academic Achievement. Vol 3. Switzerland: Springer Nature Switzerland AG; 2019:79-94.

19. David CC, Albert JRG, Vizmanos JFV. Pressures on public school teachers and implications on quality. PIDS Policy Notes. 2019; 2019(1):1-6.
20. WHO. Oral health services. 2019; https://www.who.int/oral_health/ action/services/en/. Accessed October 30, 2019.

21. Bringas FC. National training of DepEd dentists on the oral health policies and guidelines anchored on the 2019 school dental health care program. 2019; http://caraga.deped.gov.ph/ra-032-s-2019national-training-of-deped-dentists-on-the-oral-health-policiesanf-guidelines-anchored-on-the-2019-school-dental-health-careprogram/. Accessed November 7, 2019.

22. Choy HB, Wong MC. Occupational stress and burnout among Hong Kong dentists. Hong Kong Med J. 2017;23(5):480-8.

23. Baran RB. Myers Briggs Type Indicator, burnout, and satisfaction in Illinois dentists. Gen Dent. 2005;53(3):228-34; quiz 235.

24. D'Souza F, Egan SJ, Rees CA. The relationship between perfectionism, stress and burnout in clinical psychologists. Behaviour Change. 2011;28(1):17-28.

25. Chou LP, Li CY, Hu SC. Job stress and burnout in hospital employees: comparisons of different medical professions in a regional hospital in Taiwan. BMJ Open. 2014;4(2):e004185.

26. Gorter RC, Albrecht G, Hoogstraten J, Eijkman MA. Professional burnout among Dutch dentists. Community Dent Oral Epidemiol. 1999;27(2):109-16.

27. Gorter RC, Storm MK, te Brake JH, Kersten HW, Eijkman MA. Outcome of career expectancies and early professional burnout among newly qualified dentists. Int Dent J. 2007;57(4):279-85.

28. Amoafo E, Hanbali N, Patel A, Singh P. What are the significant factors associated with burnout in doctors? Occup Med (Lond). 2015;65(2):117-21.

29. Stewart NH, Arora VM. The Impact of Sleep and Circadian Disorders on Physician Burnout. Chest. 2019;156(5):1022-30.

30. Gao X, Ma KL, Wang H, Gao Q, Lei LJ, Wang T. Association of sleep quality with job burnout among Chinese coal mine staff: a propensity score weighting analysis. Sci Rep. 2019;9(1):8737.

31. Wolkow AP, Barger LK, O'Brien CS, et al. Associations between sleep disturbances, mental health outcomes and burnout in firefighters, and the mediating role of sleep during overnight work: A crosssectional study. J Sleep Res. 2019;28(6):e12869.

32. Giorgi F, Mattei A, Notarnicola I, Petrucci C, Lancia L. Can sleep quality and burnout affect the job performance of shift-work nurses? A hospital cross-sectional study. J Adv Nurs. 2018;74(3):698-708.

33. Jugale PV, Mallaiah P, Krishnamurthy A, Sangha R. Burnout and Work Engagement Among Dental Practitioners in Bangalore City: A Cross-Sectional Study. J Clin Diagn Res. 2016;10(2):ZC63-7.

34. Gorter RC. [Burnout among dentists: a question of coping]. Ned Tijdschr Tandheelkd. 2001;108(11):458-61.

35. Gorter RC, Te Brake HJ, Hoogstraten J, Eijkman MA. Positive engagement and job resources in dental practice. Community Dent Oral Epidemiol. 2008;36(1):47-54.

36. Porcalla D. Nurses' salary upgrade may take effect next year. [Internet] 2019 [Cited 2019 October 30] Available from; https://www.philstar. com/headlines/2019/10/23/1962591/nurses-salary-upgrade-maytake-effect-next-year.

37. DBM. Index of occupational services, occupational groups, classes and salary grades (105) CY 2018 Edition [Internet] 2018 [Cited 2019 June 27] Available from; https://www.dbm.gov.ph/wp-content/uploads/ OPCCB/BC/BC-2018-4-vol-i.pdf.

38. Lorenzo M. The Philippine HRH Master Plan (2005-2030). [Internet] 2008 [Cited 2019 June 27] Available from; https://www.who.int/ workforcealliance/forum/presentations/Fely_Marilyn_Elegado.pdf. 